\title{
PENGLIBATAN DAN PENDAYAUPAYAAN SOSIAL DALAM KALANGAN PESERTA PROJEK YAYASAN SEJAHTERA DI MALAYSIA
}

\author{
Sara Shakilla binti Mohd Salim ${ }^{1}$, Asnarulkhadi Abu Samah ${ }^{2}$ \\ ${ }^{1}$ Jabatan Sains Kemasyarakatan dan Pembangunan, Fakulti Ekologi Manusia, UPM Serdang \\ ${ }^{2}$ Institut Pengajian Sains Sosial, UPM Serdang
}

\begin{abstract}
This article discusses about relationship between participation of Yayasan Sejahtera (YS) project among beneficiaries in three stages namely decision making, implementation and benefit received towards social empowerment. This research examined how community participation acts as a medium towards empowerment via community development project. In community development, participation was seen as a goal when community participate directly in the decision-making process, planning and implementing development activities for fulfill community need and/or to solve problem among them. Participation provides the space of influencing and collective power among community to determine and gain control over their lives. Many benefits are acquired by the community as material and not material from the participation that can enhance their capabilities and abilities (Asnarulkhadi, 2005). This research employed quantitative approach and survey design was used. They were face-to-face interviewed using questionnaires. This study used stratified random sampling techniques and total of 305 respondents were involved in this research consisting of project participants in Kelantan, Sabah and Sarawak. Generally, this study this study found that predictors of benefit received (variance 43.8\%) in participation was the single predictors of social empowerment compared to other predictors among project participants. The rationale was based on community members have a mutual benefit projects that form a bond between them. They consist of a common group of benefit received and indirectly form a community based on their needs and interests. This can allow social empowerment to occur where there is an interaction and sharing of problems between them and thus create a bond of relationship that can shape their social processes. Community participation in the YS project can be seen as a medium to improve their quality of life through the strength of their bonding that gives the impact to understanding between them as well as shaping their ability to work together.
\end{abstract}

Keyword: Participation, social empowerment, community project, community development 
72

Community: volume 6, nomor 1, April 2020

p-ISSN: 2477-5746 e-ISSN: 2502-0544

\section{PENDAHULUAN}

Maimunah Ismail (2001) merujuk pembangunan komuniti sebagai proses memperbaiki kualiti kehidupan masyarakat dengan meningkatkan tahap kehidupan, menambah pilihan dalam peluang pekerjaan dan meningkatkan kapasiti sumber dan perkhidmatan yang sedia ada. Pembangunan komuniti menyediakan kerangka yang lebih baik untuk individu dalam masyarakat untuk bekerjasama dengan pasaran, berkongsi matlamat, tanggungjawab dan peranan yang jelas, dan kefahaman yang holistik tentang pembangunan komuniti (Community Development Agenda, 1998). Menurut Asnarulkhadi (2005) pembangunan komuniti merupakan satu gerakan yang dibentuk untuk meningkatkan taraf hidup keseluruhan anggota masyarakat dengan penglibatan aktif dan atas inisiatif mereka sendiri.

Penglibatan sebegini menyediakan ruang mempengaruhi dan berkongsi kuasa secara kolektif iaitu kuasa untuk menentukan dan memperoleh kawalan ke atas kehidupan mereka. Selain itu, Hamann (2006) dan Barney (2003) juga menyatakan bahawa salah satu usaha pembangunan komuniti adalah melalui projek kemiskinan. Bagi mengatasi masalah kemiskinan dan ketidakupayaan komuniti, maka pelbagai program dan projek telah dilaksanakan oleh pelbagai agensi termasuk Yayasan Sejahtera (YS) untuk meningkatkan taraf kehidupan diri, keluarga dan juga komuniti. Projek komuniti seperti ini dapat dilihat sebagai satu proses dalam membangunkan komuniti kerana ia adalah sebagai satu proses yang bersifat dinamik dan melibatkan satu perubahan yang bersifat progresif dan menyeluruh ke atas komuniti. Menerusi penglibatan dalam aktiviti-aktiviti yang dijalankan sepanjang program tersebut dapat membina keupayaan komuniti melalui penambahan pengetahuan, kemahiran dan pengalaman mereka. Lazimnya bagi satu pusingan yang lengkap, proses pembangunan komuniti bermula dengan penglibatan dari perancangan, pelaksanaan dan penilaian sesuatu program tersebut (Asnarulkhadi, 2003).

Teori pratik seumpama agak lumrah dalam membina dan menjayakan projek pembangunan komuniti, dan apakah ianya diamalkan oleh Yayasan Sejahtera bagi projek mereka ke atas komuniti miskin adalah satu perkara yang boleh diteliti. Sejauhmana penglibatan peserta dalam projek pembangunan komuniti dilihat mampu mempengaruhi kualiti kehidupan mereka. Penglibatan komuniti juga dapat membantu membentuk kapasiti sebahagian daripada individu tempatan untuk membuat pengawalan terhadap kehidupan mereka, untuk membawa keadilan dan untuk menjangka masalah yang mendatang (Hayes, 1981). Sementara itu, pendayaupayaan menjadi strategi utama yang digunakan oleh agensi pelaksana di luar bandar untuk mendayaupayakan ahli komuniti bagi mencapai matlamat pembangunan komuniti. Dalam melihat pendayaupayaan dan kaitannya dalam pembangunan komuniti sebagai satu program, ia

merupakan satu proses komuniti memperoleh pengalaman melalui penglibatan mereka 
Community: volume 6, nomor 1, April 2020

p-ISSN: 2477-5746 e-ISSN: 2502-0544

dalam program atau projek tersebut dan memberi kesan langsung dalam pelaksanaan projek atau program pembangunan komuniti tersebut di mana program tersebut mampu meningkatkan kesejahteraan hidup komuniti. Malah menerusi pendayaupayaan, tahap keyakinan, estim diri dan sikap proaktif dapat dipertingkatkan (Yusoff \& Aziz, 2012). Sementara itu, pendayaupayaan sosial yang diteliti dalam artikel ini pula merujuk kepada keupayaan peserta dalam konteks keupayaan individu untuk mengawal kehidupan mereka dan menguasai persekitaran melalui pembentukan hubungan dan interaksi untuk kesejahteraan hidup dan produktiviti (Mokomane, 2012) kesan daripada penglibatan projek yang disertai.

\section{TINJAUAN PUSTAKA}

Pembangunan komuniti dianggap sebagai satu usaha membawa kepada perubahan dalam kehidupan komuniti (Asnarulkhadi, 2012). Dalam membincangkan pembangunan komuniti di Malaysia, penglibatan komuniti dapat membantu membentuk kapasiti sebahagian daripada individu tempatan untuk membuat pengawalan terhadap kehidupan mereka, untuk membawa keadilan dan untuk menjangka masalah yang mendatang (Hayes, 1981). Pembangunan komuniti melibatkan satu proses dan beberapa tahap yang berbeza dalam mencapai matlamat pembangunan komuniti di mana setiap proses tersebut juga mengambil masa untuk bergerak ke proses yang seterusnya. Proses tersebut melibatkan satu bentuk perubahan yang membolehkan individu dan komuniti memahami dan menyelesaikan masalah serta membentuk suasana baru dalam kehidupan mereka (Homan 1999, Marti-Costa \& Serrano-Garcia 1983; Biddle \& Biddle 1965). Cohen dan Uphoff (1980) menambah penglibatan dilihat sebagai satu proses di mana individu dapat menghampirkan dirinya atau mempunyai hubungan dengan perancangan dan pelaksanaan sesuatu program. Beliau mencadangkan empat bentuk penglibatan dalam menghuraikan konsep cara pengukuran penglibatan komuniti luar bandar dalam pembangunan. Bentuk-bentuk penglibatan tersebut ialah: - (i) penglibatan dalam membuat keputusan, (ii) penglibatan dalam pelaksanaan, (iii) penglibatan dalam menerima faedah, (iv) penglibatan dalam penilaian. Ia menggambarkan keseluruhan pusingan program bagi sebarang usaha pembangunan luar bandar yang melibatkan penglibatan yang menyeluruh oleh komuniti. Keempat-empat peringkat penglibatan ini membentuk putaran aktiviti dalam pembangunan luar bandar. Pada dasarnya, penglibatan dalam aktiviti atau program yang berbeza selalunya terhad dan tidak sama. Penglibatan dalam pembuatan keputusan dianggap sebagai peringkat penglibatan yang paling tinggi manakala penglibatan di peringkat penilaian merupakan peringkat penglibatan yang paling rendah kerana amat kurang berlaku jika dibandingkan dengan tahap lain (Smith, 1974; Nayan; 1975). Namun begitu, penglibatan pada tahap ini akan meningkat sekiranya usaha pembangunan juga meningkat dan memerlukan satu 
sistem penilaian yang sistematik. Secara khususnya, penglibatan dalam pembuatan keputusan melibatkan proses penghasilan idea, membuat dan menilai pilihan dan juga membina rancangan. Manakala penglibatan pada peringkat pelaksanaan pula melibatkan tiga cara iaitu melalui sumbangan sumber, atau terlibat dalam aktiviti pentadbiran dan penyelarasan program atau aktiviti yang dijalankan, peserta yang terlibat dalam bentuk sumbangan sumber boleh menyumbangkan dalam bentuk kewangan, maklumat atau tenaga (Cohen \& Uphoff, 1977).

Sementara itu, penglibatan dalam peringkat penilaian pula memberi peluang kepada peserta untuk terlibat dalam pelbagai bentuk. Antaranya termasuklah menggunakan saluran politik di mana penduduk dan pemimpin lokal boleh mengkritik dan memberi cadangan tentang aktiviti yang dijalankan sebagai penilaian yang boleh dimasukkan ke dalam polisi. Selain itu, mereka juga boleh melakukan aktiviti melobi atau demonstrasi melalui organisasi seperti persatuan yang disertai untuk menyalurkan pandangan yang menjadi saluran untuk memenuhi kehendak mereka melalui perhatian yang diberikan oleh pihak atasan. Pandangan dan kritikan juga boleh disalurkan dengan mengunakan media bagi mempengaruhi pandangan awam mengenai sesuatu projek atau program yang dilaksanakan dengan harapan pihak yang terlibat sama ada meneruskan program tersebut ataupun melakukan penambahbaikan (Cohen \& Uphoff, 1980). Takrifan ini juga sama dengan yang dibuat oleh Nayan (1975) iaitu penglibatan yang menekankan tiga peringkat; perancangan, pelaksanaan dan penilaian. Lyndon et al (2012) juga menyatakan penglibatan komuniti pada kebiasaannya mempunyai beberapa elemen seperti perancangan dan pelaksanaan, pemantauan dan penilaian. Paul (1987) pula dalam perbincangan tentang penglibatan komuniti dalam projek pembangunan mendefinisikan penglibatan sebagai proses aktif bagi memberi manfaat atau memenuhi keperluan komuniti yang berkait dengan projek pembangunan dengan tujuan untuk memperbaiki kehidupan yang meliputi pendapatan, pertumbuhan peribadi, "self reliance" atau nilai lain yang dipegang oleh mereka. United Nations Asian and Pacific Development Institute (1980) melihat penglibatan sebagai proses yang dilakukan secara sukarela dalam empat aspek, iaitu; (i) penglibatan dalam membuat keputusan, (ii) penglibatan dalam pelaksanaan program-program dan projek-projek pembangunan, (iii) penglibatan dalam susulan balas dan penilaian ke atas projek dan program pembangunan dan (iv) penglibatan dalam pembahagian hasil yang diperoleh daripada pembangunan tersebut. Penglibatan merupakan satu bentuk tingkah laku yang melibatkan komuniti mengambil inisiatif untuk turut serta dalam apa juga rancangan, program atau aktiviti yang bertujuan membawa perubahan ke arah kualiti hidup yang lebih baik.

Sementara itu, pendayaupayaan itu juga boleh dilihat bukan hanya sebagai satu proses malah ia juga satu produk (hasil) (Asnarulkhadi, 2009). Ia dilihat sebagai satu proses bila mana berlaku dalam proses pembangunan komuniti melalui penglibatan. 
Community: volume 6, nomor 1, April 2020

p-ISSN: 2477-5746 e-ISSN: 2502-0544

Melalui penglibatan banyak faedah yang mungkin diperolehi oleh komuniti sama ada bersifat kebendaan dan bukan kebendaan yang mampu meningkatkan keupayaan, kemampuan dan kebolehan mereka. Hasilnya ialah komuniti yang berdikari dan berdaya upaya. Kajian Asnarulkhadi (2009) meneliti enam indikator pendayaupayaan komuniti sebagai satu proses yang terdiri daripada kesedaran dan keupayaan untuk mengambil tindakan, keupayaan dalam melatih kebolehan diri sendiri, kemampuan mengawal kehidupan, pembangunan diri melalui penambahbaikan dalam keyakinan diri, kemahiran dan pengetahuan, memperoleh kuasa dengan pihak lain serta kemampuan melakukan penilaian ke atas diri sendiri. Adams (1990) mendefinisikan pendayaupayaan sebagai satu proses apabila individu, organisasi dan komuniti mempunyai kebolehan dalam mengawal kehidupan mereka mencapai matlamat untuk kesejahteraan hidup. Dalam erti kata lain, ia merupakan satu proses perubahan kepada ketidakupayaan atau tiada kuasa kepada mempunyai kuasa untuk membuat pilihan yang boleh mempengaruhi kehidupan. Rappaport (1987) dan Zimmerman (1988) menambah pendayaupayaan merupakan kebolehan individu untuk mengawal kehidupan mereka dalam aspek sosial, ekonomi dan psikologi melalui (i) akses kepada pengetahuan dan kemahiran, (ii) pembuatan keputusan, (iii) pembentukan efikasi diri, penglibatan dan keupayaan mengawal keadaan.

Sementara itu, pendayaupayaan sebagai satu produk lebih sukar untuk dinilai dan diukur kerana mempunyai perbezaan maksud dan pengukuran dalam konteks komuniti yang berbeza. Kesukaran ini juga boleh berlaku dalam konteks perbezaan individu walaupun dalam program komuniti yang sama (Zimmerman, 1988). Beliau menambah pemahaman berkaitan pendayaupayaan lebih mudah difahami dan diukur sebagai proses yang dinamik berbanding pengukuran sebagai hasil (produk) kerana matlamat pendayaupayaan sebagai hasil tidak selari dengan pengalaman individu, organisasi dan komuniti yang mempunyai konteks persekitaran dan tempoh masa yang berbeza. Pendayaupayaan lebih konsisten dilihat sebagai satu proses yang bersifat dinamik dan berterusan yang mana melibatkan (i) pendayaupayaan diri, (ii) pembangunan dalam kumpulan kecil, (iii) organisasi komuniti, (iv) rakan kongsi dan (v) tindakan sosial dan politik (Jackson et al, 1989; Labonte, 1994; Rissel, 1994). Pendayaupayaan komuniti sebagai satu proses yang memaksimakan potensi sebagai individu dan berubah ke arah tindakan bersama (Laverack, 2001). Dalam melihat perkaitan antara hubungan penglibatan dan pendayaupayaan, kebanyakan sarjana berpendapat bahawa penglibatan membawa kepada pendayaupayaan di mana penglibatan muncul terlebih dahulu dalam aspek pembangunan komuniti kerana pendayaupayaan menggambarkan keupayaan individu menguasai kehidupan kesan daripada penglibatan mereka dalam pembangunan walaupun keputusan analisis mendapati hubungan dan hala tuju kedua-duanya adalah kompleks (Saegart \& Winkel, 1996). Namun begitu, terdapat banyak pendokong teori pendayaupayaan mengatakan 
dan mempercayai bahawa melalui penglibatan dapat membentuk pendayaupayaan dalam kalangan ahli komuniti sama ada secara individu mahupun melalui organisasi komuniti (Geidam, 2012; Speer, Peterson, Armsteed \& Allen, 2012; Peterson et.al, 2006; Schulz, Israel, Zimmerman \& Checkoway, 1995).

\section{METODE PENELITIAN}

Kajian ini merupakan kajian survei menggunakan soal selidik. Kajian ini menggunakan teknik persampelan rawak berstrata untuk memilih responden daripada 13 projek di ketiga-tiga negeri iaitu Kelantan, Sabah dan Sarawak. Sebanyak 305 responden terlibat dalam kajian ini. Persampelan berstrata membolehkan bilangan peserta YS yang tidak seragam pada setiap lokasi mempunyai peluang yang sama untuk dipilih sebagai sampel. Ia merupakan teknik persampelan kebarangkalian yang mana penyelidik membahagikan keseluruhan populasi kepada strata yang berbeza, kemudian memilih secara rawak subjek akhir secara berkadar daripada strata yang berbeza. Kaedah ini dipilih kerana ia mengambil kira ciri yang wujud dalam populasi di pelbagai peringkat. Rajah 1 di bawah menunjukkan prosedur persampelan berstrata dalam kajian.

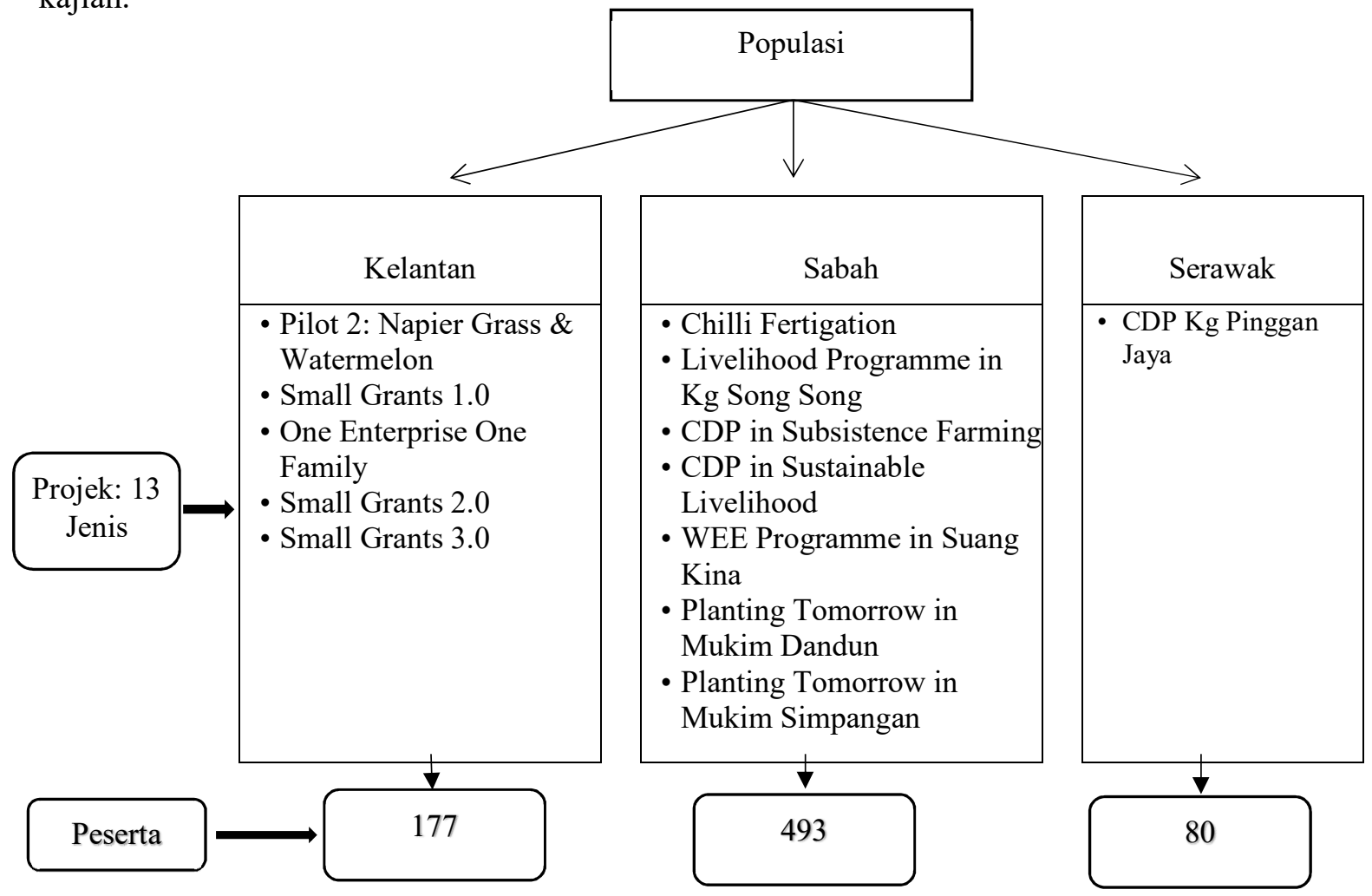

Rajah 1: Prosedur Persampelan Pelbagai Peringkat 
Community: volume 6, nomor 1, April 2020

p-ISSN: 2477-5746 e-ISSN: 2502-0544

Kajian ini menggunakan soal selidik yang dibina oleh Cohen \& Uphoff (1980) dalam model penglibatan dan diadaptasikan oleh Haris (1996) dan Mohammed Bashir (2013b) yang terdiri daripada 28 item merangkumi pembuatan keputusan, pelaksanaan dan penerimaan faedah. Penggunaan soal selidik ini dikatakan sesuai dengan kajian memandangkan pembentukan item-itemnya yang bersesuaian dengan latar belakang sosio demografi, persekitaran dan konteks kajian yang ingin dibuat oleh penyelidik. Sementara itu, bagi pendayaupayaan sosial pula, penyelidik menggunakan idea Putnam (2000) yang terdiri daripada 12 item merangkumi ikatan kebersamaan, jalinan hubungan dan rangkaian kerjasama. Pembinaan soal selidik diambil serta diadaptasikan daripada gabungan beberapa orang sarjana iaitu Larsen et.al (2004), Wu et al., (2006) dan Park, Lee, Choi \& Yoon (2012). Dalam kajian ini, Partial Least Squares Structural Equation Modelling (PLS-SEM) digunakan bagi melihat pengaruh hubungan antara peringkat penglibatan yang terdiri daripada tiga dimensi iaitu peringkat penglibatan (pembuatan keputusan, pelaksanaan dan penerimaan faedah) ke atas pendayaupayaan sosial. Penggunaan PLS-SEM memudahkan kajian ini dilakukan kerana ia melibatkan diagram atau visual yang bermakna di samping setiap prosedur pelaksanaannya yang sistematik dapat menguji setiap pemboleh ubah dan item berdasarkan objektif kajian dan persoalan kajian khususnya.

\section{TEMUAN DAN PEMBAHASAN}

Umumnya, kajian ini mendapati bahawa peramal penerimaan faedah (varians $43.8 \%$ ) dalam penglibatan merupakan peramal tunggal ke atas pendayaupayaan sosial berbanding peramal lain iaitu pembuatan keputusan dan pelaksanaan dalam kalangan peserta projek. Dalam konteks ini, pendayaupayaan sosial peserta merangkumi hubungan dan kerjasama dengan pihak YS serta pihak-pihak lain serta ahli komuniti lain yang terlibat secara langsung dalam projek. Namun begitu, hubungan tersebut boleh dipertingkatkan dalam tempoh projek yang lebih lama di samping tunjuk ajar dan pendedahan kepada komuniti tentang kepentingan hubungan dan kerjasama dalam komuniti. Ini penting kerana komuniti yang mendapat sokongan sosial mampu untuk berdiri sendiri dan berdikri yang mana sifat tersebut mampu menyumbang kepada pembangunan yang mampan selain daripada pembentukan pendayaupayaan sosial dalam diri mereka. Selain itu juga Barom (2000) membuktikan bahawa persoalan kefahaman dan penghayatan individu mengenai makna dan tuntutan kerjasama mempengaruhi sama ada ke arah menjalinkan kerjasama atau sebaliknya. Jika individu dapat memahami dan menghayati sesuatu perkara dengan individu lain daripada perspektif yang sama, dan diperkukuhkan dengan pengalaman yang hampir serupa, maka sesuatu tindakan secara bersama mudah dijalinkan. Kekuatan ikatan kebersamaan antara ahli komuniti memberi impak yang kuat antara mereka untuk saling mengambil tahu sekaligus membentuk daya upaya dalam menangani masalah secara bersama. Begitulah yang berlaku hasil daripada kajian ini yang menunjukkan hubungan yang signifikan antara penerimaan faedah dengan pendayaupayaan sosial komuniti. Komuniti yang telah berdayaupaya merupakan 
komuniti yang mampu berdikari dan membuat keputusan dengan bijak. Di sini pendayaupayaan dilihat sebagai satu produk (hasil) daripada pembangunan komuniti itu sendiri. Komuniti yang mempunyai daya mampu meningkatkan potensi diri mereka melalui pembelajaran dalam merancang, merangka strategi, membuat keputusan, mencari dan menguruskan sumber dalam komuniti dan memimpin.

Komuniti yang berjaya mempunyai elemen pendayaupayaan akan mudah mencapai matlamat sekaligus kesejahteraan hidup dapat dinikmati. Desai (2008) mengatakan pendayaupayaan boleh dicapai menerusi tiga cara iaitu kuasa, pengaruh dan penglibatan. Menurut beliau, seseorang individu yang mengambil bahagian dalam aktiviti komuniti mampu mempengaruhi proses aktiviti tersebut. Sejauh mana seseorang itu boleh mempengaruhi proses aktiviti bergantung kepada kuasa yang dimiliki oleh individu. Ben-Meir (2004) mengatakan pembangunan komuniti berlaku apabila ahli komuniti bekerjasama membentuk dan menguruskan projek untuk diri mereka sendiri yang merangkumi faedah sosio-ekonomi, politik dan persekitaran. Manakala Cohen dan Uphoff (1971) pula menyatakan bahawa anggota komuniti perlu melibatkan diri dalam aspek yang menyeluruh merangkumi pembuatan keputusan, pelaksanaan dan penerimaan faedah serta penilaian dan memastikan aktiviti tersebut memberi kesan yang positif dalam kehidupan mereka. Oleh itu, pendayaupayaan dalam diri komuniti merupakan satu medium yang boleh terbentuk melalui proses (penglibatan) yang mengizinkan individu, kumpulan atau komuniti mendapat dan menunjukkan kebolehan dan kemampuan dalam memahami, menginterpretasi masalah dan/atau keperluan (May, Mendelson \& Ferketich, 1995).

Dalam konteks projek YS, komuniti berupaya menjalin hubungan terus dan rapat dalam kalangan peserta dan komuniti setempat mahupun dengan pihak luar apabila mereka aktif melibatkan diri dalam projek. Penglibatan aktif dilihat sebagai faedah yang diperolehi oleh komuniti mampu mengizinkan medium komunikasi berlaku dan pertukaran idea dan secara tidak langsung berlaku penambahan maklumat baru, jaringan kerjasama dan sokongan antara satu sama lain. Begitu juga dengan penglibatan yang mengizinkan sesuatu masalah yang berlaku dapat diselesaikan melalui perbincangan dan tindakan kolektif antara peserta.

Secara kesimpulan, peserta YS lebih cenderung untuk melibatkan diri dalam projek komuniti bagi memperolehi faedah sama ada dalam bentuk material, sosial mahupun personal. Penglibatan peserta dalam projek YS mampu mempengaruhi tahap kehidupan mereka ke arah yang lebih baik dan mampu mengawal kehidupan melalui pendayaupayaan yang terbentuk dalam diri mereka terutama dalam aspek perhubungan sosial mereka. Jika dilihat sendiri pendayaupayaan di peringkat komuniti merujuk kepada tindakan kolektif untuk meningkatkan kualiti kehidupan dalam komuniti (Zimmerman, 2000). Peterson \& Zimmerman (2004) pula berpendapat pembentukan rangkaian hubungan antara komuniti dengan agensi-agensi lain membantu menjelaskan sejauhmana sesebuah komuniti berdayaupaya. Ini secara tidak langsung mengukuhkan lagi bahawa pendayaupayaan daripada penglibatan komuniti dapat memberi kesan langsung dalam konteks sosial mereka. Sementara itu, Iscoe (1974) pula mengenalpasti 
Community: volume 6, nomor 1, April 2020

p-ISSN: 2477-5746 e-ISSN: 2502-0544

komuniti yang kompeten merupakan komuniti yang mempunyai ahli yang berkemahiran, berpengalaman, bekerjasama, mengenalpasti kehendak komuniti membina strategi bagi melaksanakan tindakan bagi memenuhi kehendak mereka. Pada peringkat ini, ia merupakan satu proses dalam bentuk yang berterusan yang dinamik melibatkan pendayaupayaan individu, organisasi dan komuniti. Melalui penglibatan, individu dan kumpulan yang terdapat dalam komuniti yang telah didayaupayakan mampu meningkatkan sokongan antara satu sama lain, mengenal pasti konflik dalam komuniti, meningkatkan pengaruh dan kawalan ke atas kualiti hidup dalam komuniti mereka. Pendayaupayaan di peringkat komuniti juga mampu untuk mempengaruhi keputusan dan membuat perubahan dalam sistem sosial mereka. Pembangunan komuniti diyakini dapat berfungsi dengan baik apabila semua pihak saling bekerjasama bagi menjayakannya (Community Glossary, 2009). Keupayaan dan kemampuan komuniti dalam menangani masalah dan mencapai keperluan hidup menunjukkan komuniti telah berdayaupaya yang sekaligus mampu memberi kesejahteraan hidup yang berterusan dalam komuniti.

\section{PENUTUP}

Penglibatan seseorang dalam program pembangunan bukan sahaja memberi faedah kepada dirinya malah tetapi juga kepada organisasi dan juga komuniti. Hardina (2003) telah melihat kepentingan dan faedah penglibatan kepada individu, kumpulan, organisasi atau komuniti dalam pembangunan yang banyak dibincangkan secara meluas oleh para sarjana terutama kesan penglibatan tersebut ke atas pembentukan pendayaupayaan. Melalui penglibatan, banyak faedah diperoleh oleh komuniti sama ada bersifat kebendaan dan bukan kebendaan yang mampu meningkatkan keupayaan, kemampuan dan kebolehan mereka (Asnarulkhadi, 2005). Pendayaupayaan komuniti pula menggambarkan komuniti yang mempunyai kuasa dalam menentukan bentuk pembangunan yang diingin dan mempunyai hak dalam membuat keputusan. Ia boleh dicapai melalui proses penglibatan yang terdiri daripada pelbagai tahap. Selain itu, pendayaupayaan merupakan satu proses yang kompleks di mana ahli komuniti melibatkan diri dan terikat dengan aktiviti untuk mencapai matlamat. Dalam proses pencapaian matlamat itu membolehkan komuniti melatih dan mempraktis keupayaan mereka dalam membawa dan membuat perubahan dalam kehidupan mereka (Asnarulkhadi, 2009).

Dalam proses penglibatan itu sendiri ia perlu melibatkan pendekatan yang sesuai dengan matlamat yang ingin dicapai. Proses yang menggalakkan penglibatan aktif lagi bebas dalam kalangan ahli komuniti mengambil tindakan secara sendirian tanpa dibatasi oleh prosedur yang tegar daripada pihak luar dapat menyemarakkan lagi pendayaupayaan berlaku. Model proses yang mengamalkan kaedah atau pendekatan 
bawah-atas (Batten, 1957) atau model matlamat sosial (Rothman \& Papell, 1978) dalam usaha membangunkan komuniti mempunyai kekuatan mendayaupayakan komuniti. Justeru itu, peserta projek seharusnya melibatkan diri daripada peringkat awal perancangan aktiviti sehingga peringkat penilaian. Dengan cara ini, mereka lebih memahami permasalahan yang berlaku dalam komuniti dan mampu untuk mempelajari cara mengatasinya. Oleh itu, pelaksanaan sesebuh projek dalam komuniti dapat mewujudkan komuniti yang berdikari dan tidak bergantung dalam usaha memperbaiki kualiti hidup ke arah lebih baik. Selain itu, dalam mendayaupayakan komuniti pelbagai aspek perlu diberi penekanan terutama dalam memperluaskan lagi bentuk program dan aktiviti dan selain daripada latihan dan kemahiran. Bentuk program atau aktiviti tersebut perlu selari ke arah membentuk keupayaan dalam diri komuniti. Ini kerana komuniti merupakan kumpulan sasaran dalam pembangunan yang menjadi penggerak, pelaksana, pemantau, penilai selain daripada menjadi perancang bersama daripada peringkat awal program. Jika aspek sedemikian diberi penekanan dalam pelaksanaan sesuatu program atau aktiviti, ia boleh mengizinkan pendayaupayaan berlaku dalam diri komuniti. Secara asasnya, proses pembangunan komuniti melibatkan kemampuan komuniti menentukan hala tuju mereka dan corak perubahan atau kemajuan yang dihasratkan sesuai dengan konteks persekitaran kehidupan mereka (Asnarulkhadi, 2011). Pendapat ini turut disokong oleh Parsons (1991), Barr (1995) dan Zimmerman \& Rappaport (1988) di mana dalam konteks pembangunan komuniti melihat pendayaupayaan sebagai kemampuan individu melakukan dan mempengaruhi perubahan sesuai dengan keperlaun dan didorong oleh rasa bertanggungjawab, berdikari, tolong - menolong dalam membebaskan diri daripada masalah secara sukarela tanpa paksaan sehingga dapat menikmati kehidupan yang sejahtera dan berkualiti.

\section{DAFTAR PUSTAKA}

Adams, R. (2003). Social work and empowerment. Edisi ke-3, New York, NY: Palgrave Macmillan.

Asnarulkhadi Abu Samah (2003). Pengenalan Pembangunan Komuniti. Serdang, Selangor: Percetakan Selaseh Sdn Bhd.

Asnarulkhadi Abu Samah (2005) Pendayaupayaan Komuniti Melalui Penglibatan : Satu Penilaian Umum Terhadap Pembangunan Komuniti, Malaysian Journal of Social Policy \& Society, Volume 2.

Asnarulkhadi Abu Samah \& Fariborz Aref (2009). People's Participation in Community Development: A Case Study in a Planned Village Settlement in Malaysia. World Rural Observations 2009; 1 (2):45-54, Marsland Press. 
Community: volume 6, nomor 1, April 2020

p-ISSN: 2477-5746 e-ISSN: 2502-0544

Asnarulkhadi Abu Samah. (2011). Pendayaupayaan komuniti ke arah pemupukan komuniti sivil berkualiti. Dalam Pembangunan komuniti: membina keupayaan dan potensi masyarakat, (hlm. 104-119). Serdang: Universiti Putra Malaysia.

Barney I (2003). Bussiness, Community Development and Sustainable Livelihood Approach. Community Development Journal 38 (3). 255-265.

Barr, R. (1995). "Empowering communities- beyond fashionable rhetoric? Some refelctions on Scottish experience" dalam Community Development Journal, 30, 2, 121-132.

Ben-Meir, J. (2004). International Journal of Sociology and Social Policy, 24,12, 2542.

Cohen, J. M., \& Uphoff, N. T. (1980). Participation's place in rural development: Seeking clarity through specificity. World Development, 8(3), 213-235.

Community Glossary (2009). Diambil daripada http://www.findmehere.com/search/dictionary/c index. html\#com pada 12 Dec 2018.

Desai, V. (2008). Community participation in development, In The companion to development studies. Edisi ke-2. (hlm. 115-119). London: Hodder Education.

Haman R (2006). Can Business make Decisive Contributions to Develompent? Towards a Research agenda on Corporate Citizenship and Beyond. Development Southern Africa 23 (2), 175-195.

Hardina, D. (2003). Linking citizen participation to empowerment practice. Journal of Community Practice, 11(4), 11-38.

Haris Abdul Wahab. (1996). Penglibatan peserta dalam program pembangunan komuniti di Kampung Buloh, Kelantan. (Tesis Sarjana yang tidak diterbitkan). Universiti Pertanian Malaysia.

Geidam, A. A. (2012). Assessment of participation in afforestation programme and relationship to empowerment. International Journal of Academic Research in Business and Social Sciences, 2(8), 310-315.

Iscoe, I. (1974). Community psychology and the competent community. American Psychologist, 29(8), 607-613.

Larsen, L., Harlan, S. L., Bolin, B., Hackett, E. J., Hope, D., Kirby, A., Wolf, S. (2004). Education and research social capital and civic action. Journal of Planning Education and Research, 24(64). 
Laverack, G. (2001). An identification and interpretation of the organizational aspects of community empowerment. Community Development Journal, 36(2), 134-145.

Maimunah Ismail (2001). Malaysian Women in Rural Development and Entrepreneurship: From Rural Producers to Urban Entrepreneur. Asean Academic Press, London.

May, K.M. Mendelson,C., \& Ferketich, S. (1995). Community Empowerment in rural health care. Public Health Nursing, 12 (1), 25-30.

Mohammed Bashir Saidu. (2013a). Participation in Microfinance scheme as a medium for empowerment among farmers community in Kano State, Nigeria. Universiti Putra Malaysia.

Mokomane, Z. (2012). Role of families in social and economic empowerment of individuals. United Nation, New York.

Park, D., Lee, K., Choi, H., \& Yoon, Y. (2012). Factors influencing social capital in rural tourism communities in South Korea. Tourism Management. 33(6), 15111520.

Parson. R.J (1991). "Empowerment: Purpose and Practice in Social work", Social work with the group:14,2, 7-21.

Peterson, N. A., Lowe, J. B., hughey, J., Reid, R. J., Zimmerman, M. A., \& Speer, p. W. (2006). Measuring the intrapersonal component of psychological empowerment: Confirmatory factor analysis of the sociopolitical control scale. Community Psychology, 38, 287-297.

Putnam, R. (1995). Tuning In, Tuning Out: The Strange Disappearance of Social Capital in America. Political Science and Politics, December. pp.664-683.

Wu, J. B., hom, P. W., Tetrick, L. E., Shore, 1., M., Jia, L., Li., C., \& Song, L. J. (2006). The norm of reciprocity: Scale development and validation in the Chinese context. Management and Organization Review, 2(3), 377-402.

Zimmerman, M., \& Rappaport, J. (1988). Citizen participation, preceived control, and psychological empowerment. American Journal of Community Psychology, 16(5), 725-750.

Zimmerman, M. A. (2000). Empowerment theory: Psychological, organizational and community level of analysis. Dalam J. Rappaport \& E. Seidman (Editor), Handbook of Community Psychology (hlm. 43-59). New York: Kluwer Academic/Plenum Publishers. 